\title{
Evaluation of Face Mask Filtering EfFicienCy USING High-END SCanNing Mobility Particle Sizer
}

\author{
Adnan Masic*, Boran Pikula, Vahidin Hadziabdic, \\ Midhat Mehuljic \& Jasmin Bektesevic
}
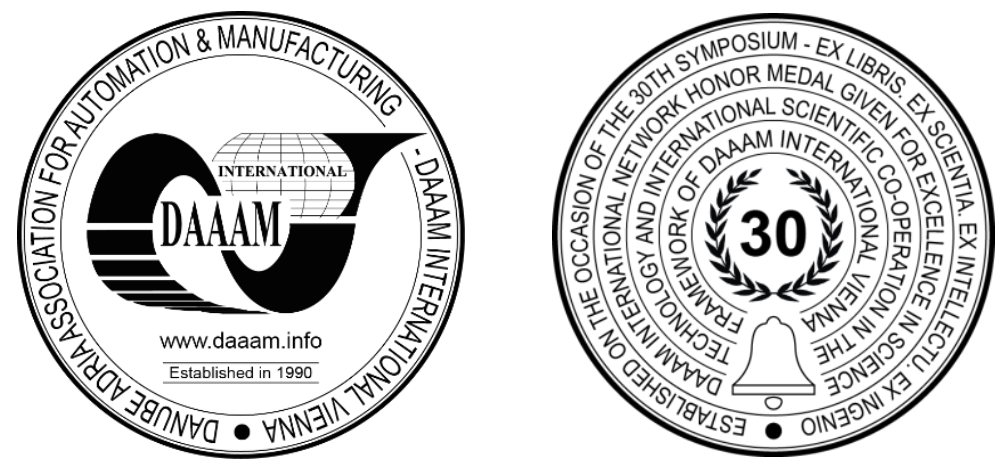

This Publication has to be referred as: Masic, A[dnan]; Pikula, B[oran]; Haziabdic, V[ahidin]; Mehuljic, M[idhat] \& Bektesevic, J[asmin] (2020). Evaluation of Face Mask Filtering Efficiency Using High-End Scanning Mobility Particle Sizer, Proceedings of the 31st DAAAM International Symposium, pp.0224-0226, B. Katalinic (Ed.), Published by DAAAM International, ISBN 978-3-902734-29-7, ISSN 1726-9679, Vienna, Austria

DOI: $10.2507 / 31$ st.daaam.proceedings.030

\begin{abstract}
An advanced system for determination of face mask efficiency is developed and presented in this paper. It is based on a high-end scanning mobility particle sizer (SMPS), which was able to detect nanoparticles from the diameter of $10 \mathrm{~nm}$ up to $1000 \mathrm{~nm}$ in 129 equidistant channels. Two fitting installations for face masks were used: a mannequin doll head, to simulate realistic use of face mask and a tight-fit system which prevents the air leak. The SMPS-based system was able to determine mask efficiency for different particle sizes.
\end{abstract}

Keywords: COVID-19; Nanoparticles; Scanning mobility particle sizer; Face mask.

\section{Introduction}

One of the most widely used measures against COVID-19 is the mandatory face mask. However, there is a concern about their efficiency to block the virus, leading to the global debate on the issue. Many studies, as pointed in this overview [1], confirm certain effect of the face masks, with overall conclusion that they reduce the risk of infection to some extent. Different materials and mask designs were evaluated in [2] with similar conclusion: the masks should be part of the strategy, but that's not enough, so other measures such as keeping the distance are combined for better protection. Researchers in [3] argue that wearing a face masks for entire population is costly, but that cost is more acceptable than closing schools and businesses. Investigation [4] uses the mathematical modelling to examine the epidemiological impact of face masks and concludes that face masks can reduce total infections and deaths.

Focus of this paper is the evaluation of the face mask filtering efficiency as a function of particle's size. This is also important for understanding potential connection between air pollution (by suspended particles) and probability of transmission of the virus (through the air). Considering that the order of magnitude of coronavirus diameter is about 100 $\mathrm{nm}$, we need an instrument which can detect such a small particle. Advanced spectrometer was used for that purpose. Research question is: to what extent is this system suitable for evaluation of the face mask filtering efficiency in context of COVID-19? 


\section{Experimental setup}

The core component of our experimental system is the scanning mobility particle sizer (SMPS). It is a complex spectrometer which consists of a condensation particle counter (CPC), a differential mobility analyser (DMA) and a charge conditioner (Fig. 1.). Depending on the characteristics of the DMA, the SMPS can be configured for certain span of particle diameters.

We have used Grimm 5.416 high-end SMPS with long DMA which is able to separate particles from $10 \mathrm{~nm}$ to 1000 $\mathrm{nm}$ in 129 channels, equidistant on a logarithmic scale. A soft X-ray device was used as the charge conditioner. Scanning mode (alternating upscan and downscan) was used for all measurements. One scan takes about 4 minutes ( 8 minutes for both upscan and downscan). Room temperature was $(20 \pm 1){ }^{0} \mathrm{C}$ and relative humidity was between $40 \%$ and $50 \%$ during the test.

More details about this system and other in-house developed components are described in [5], [6], [7] and [8]. Standard surgical face mask was tested, since it is commonly used worldwide. The tight-fit system (Fig. 1. right) was achieved by attaching the piece of mask's material to a borosilicate glass funnel using a strong duct tape.
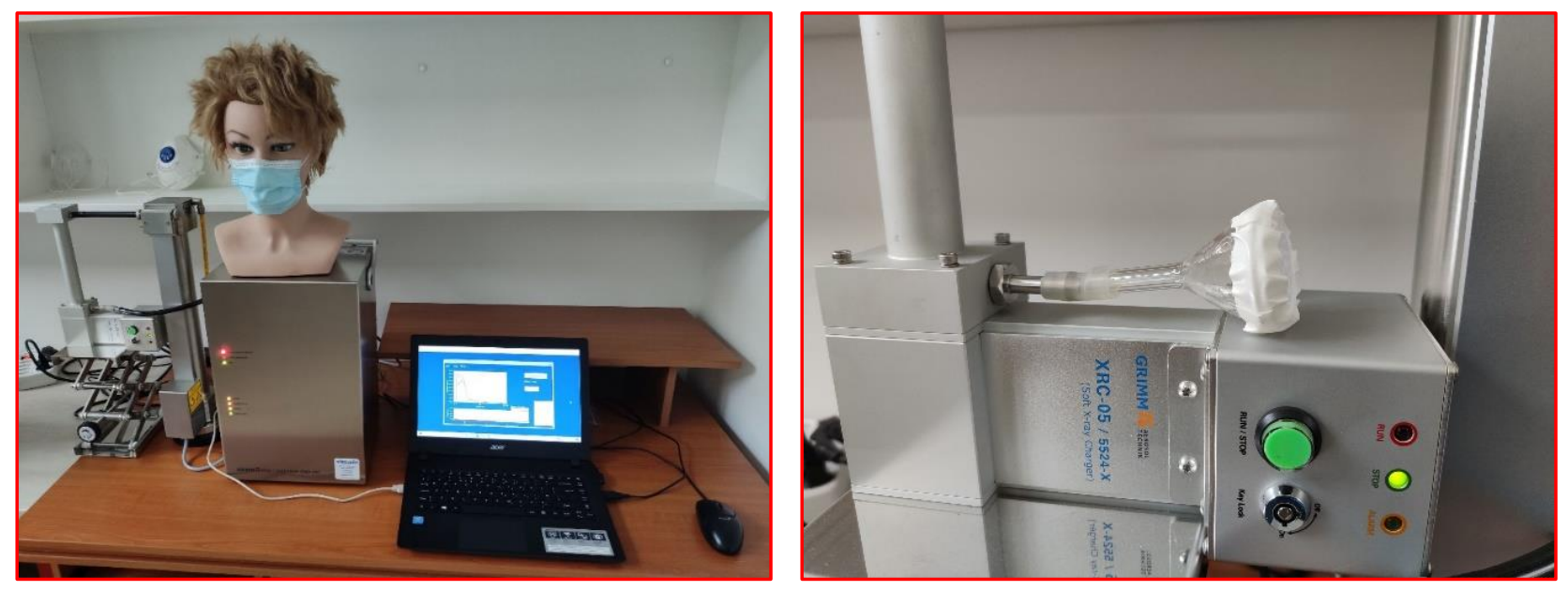

Fig. 1. Face mask test setup: the mannequin doll head and tight-fit system

\section{Results}

In order to adrress our research question, three measurements were performed:

- without mask, to determine background particle concentration,

- $\quad$ with mask on mannequin doll head, to simulate breathing of real person (Fig. 1. left),

- $\quad$ with piece of mask material attached to the tight-fit inlet, to prevent air leaks (Fig. 1. right).

For each test, average value of two passes (one upscan and one downscan) was calculated. Background concentration was 7077 particles per $\mathrm{cm}^{3}$ of air. Average value of measurements with mask on mannequin doll head was 4063 particles per $\mathrm{cm}^{3}$ of air, i.e. reduction of $42,58 \%$ of total particle count. Once the part of the mask was attached to the tight-fit system, total counts dropped significantly, to 1450 particles per $\mathrm{cm}^{3}$ of air, which is a reduction of $79,52 \%$ relative to the background concentration (Fig. 2. right).

Three histograms (Fig. 2. left) show the full spectrum of particles, from $10 \mathrm{~nm}$ to $1000 \mathrm{~nm}$, for these three cases. Background spectrum (case without mask in Fig. 2.) shows large number of ultrafine particles (UFPs) which have diameter less than $100 \mathrm{~nm}$. When the face mask was mounted on mannequin doll head, histogram was reduced almost uniformly across the spectrum. However, the tight-fit system prevented sideways air leak, and filtering efficiency was improved significantly, especially for UFPs.

From these histograms we can see that the mask reduces particle concentrations significantly for particles whose diameter is comparable to the diameter of coronavirus. Hence, from mechanical point of view, wearing the mask will reduce the risk from infection. One of the most common problems with face masks is the air leak (part of air flow which passes around the mask during a breath). Particles smaller than $100 \mathrm{~nm}$, due to very low inertia, are carried by the leaking air, which is significant problem in realistic situations. Preventing the sideways air leak is very important for good filtering efficiency of the face mask. 

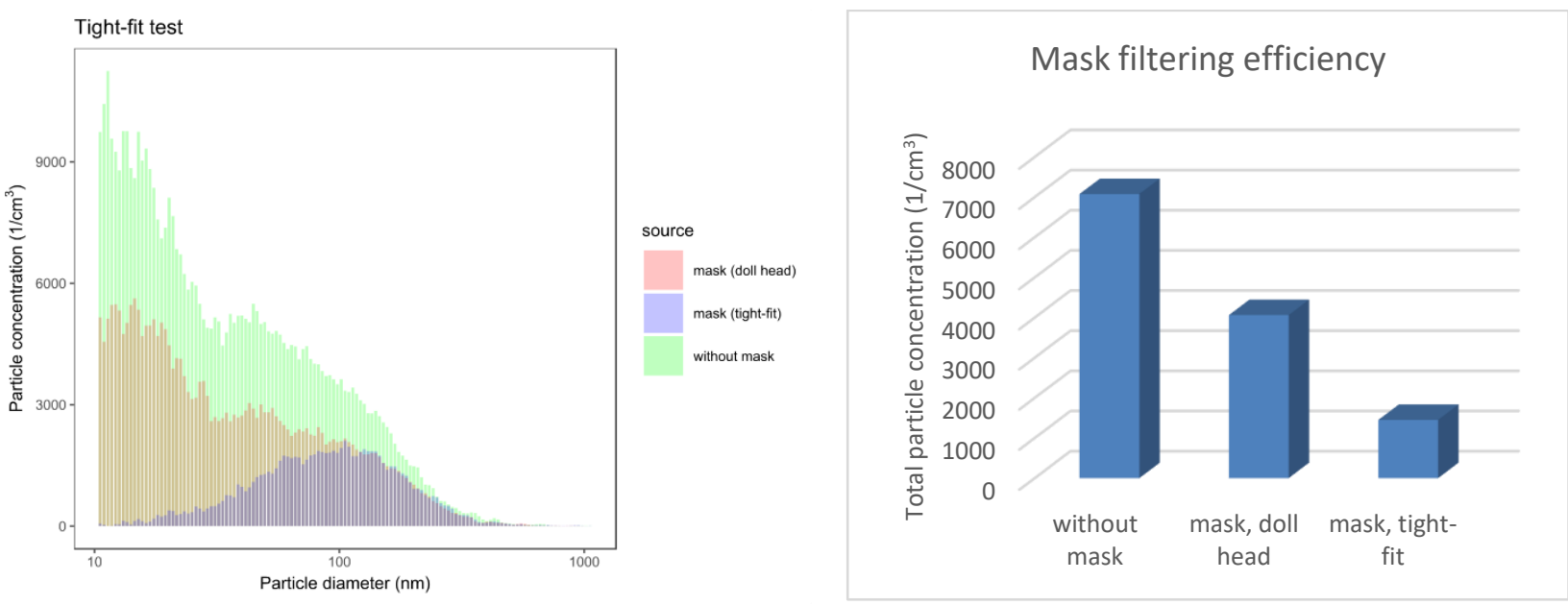

Fig. 2. The results: histogram and total particle concentration for tests: without mask, with mask on mannequin doll head and mask with tight-fit system

\section{Conclusion}

High-end SMPS spectrometer was successfully adapted for measurements of face mask filtering efficiency. Two fitting system were used: mannequin doll head and tight-fit system. Results show that the test mask filtered out round $43 \%$ of all particles when mannequin doll head was used. However, when the tight-fit system was used, filtering efficiency increased to around $80 \%$. Histograms of mass spectrometry show that smallest nanoparticles can bypass the mask if there is any air leak. In conclusion, this investigation shows that:

- $\quad$ SMPS based system, as described here, is capable to evaluate face mask filtering efficiency for nanoparticles,

- standard surgical face mask significantly reduces probability of transmission of nanoparticles (such as the coronavirus),

- problem of air leak is serious shortcoming of standard face masks, which enables nanoparticles to bypass the mask during the breath.

In the future work more types of masks should be tested and fitting problem should be investigated in more details.

\section{References}

[1] Peeples, L. (2020). Face masks: what the data say, Nature, Vol. 586, pp. 186-189, DOI: 10.1038/d41586-020-028018

[2] Chua, M. H. et al. (2020). Face Masks in the New COVID-19 Normal: Materials, Testing, and Perspectives, Research, Vol. 2020, DOI: 10.34133/2020/7286735

[3] Schünemann, H. J. et al. (2020). Use of facemasks during the COVID-19 pandemic, The Lancet, Vol. 8, No. 10, pp. 954-955, DOI: 10.1016/S2213-2600(20)30352-0

[4] Worby, C. J. \& Chang, H. H. (2020). Face mask use in the general population and optimal resource allocation during the COVID-19 pandemic, Nature Communications, Vol. 2020, No. 11, pp. 40-49, DOI: 10.1038/s41467-020-17922$\mathrm{x}$

[5] Masic. A.; Bibic, D.; Pikula, B.; Blazevic, A.; Huremovic, J. \& Zero, S. (2020). Evaluation of optical particulate matter sensors under realistic conditions of strong and mild urban pollution. Atmospheric Measurement Techniques, Preprint, DOI: 10.5194/amt-2020-237

[6] Masic, A.; Bibic, D. \& Pikula, B. (2019). On the applicability of low-cost sensors for measurements of aerosol concentrations, Proceedings of the 30th DAAAM International Symposium, pp.0452-0456, B. Katalinic (Ed.), Published by DAAAM International, ISBN 978-3-902734-22-8, ISSN 1726-9679, Vienna, Austria DOI: 10.2507/30th.daaam.proceedings.060

[7] Masic, A.; Pikula, B.; Bibic, D.; Musemic, R. \& Halac, A. (2018). Calibration and Assessment of Low-cost Dust sensors, Proceedings of the 29th DAAAM International Symposium, pp. 523-528, B. Katalinic (Ed.), Published by DAAAM International, ISBN 978-3-902734-xx-X, ISSN 1726-9679, Vienna, Austria, DOI: 10.2507/29th.daaam.proceedings.075

[8] Masic. A.; Bibic, D.; Pikula, B.; Dzaferovic-Masic, E. \& Musemic, R. (2019). Experimental study of temperature inversions above urban area using unmanned aerial vehicle. Thermal Science, Vol. 23, No. 6A, pp. 3327-3338, DOI: 10.2298/TSCI180227250M 